\title{
Design Diversity of HEVs with Example Vehicles from HEV Competitions
}

$$
\text { ANL/ES/CP--89013 }
$$

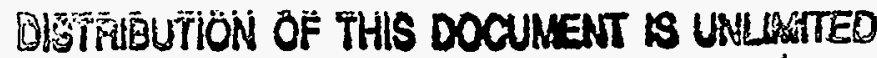

\author{
M. Duoba, R. Larsen, N. LeBlanc \\ CONF-960204--9
}

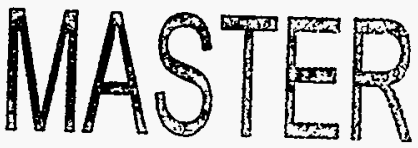

\section{ABSTRACT}

Hybrid Electric Vehicles (HEVs) can be designed and operated to satisfy many different operational missions. The three most common HEV types differ with respect to component sizing and operational capabilities. However, HEV technology offers design opportunities beyond these three types. This paper presents a detailed HEV categorization process that can be used to describe unique HEV prototype designs entered in college and university-level HEV design competitions. We explored possible energy management strategies associated with designs that control the utilization of the two on-board energy sources and use the competition vehicles to illustrate various configurations and designs that affect the vehicle's capabilities. Experimental data is used to help describe the details of the power control strategies which determine how the engine and electric motor of HEV designs work together to provide motive power to the wheels.

\section{INTRODUCTION}

In the past several years, researchers have increased the level of detail used to describe the attributes and operational characteristics of hybrid electric vehicles (HEVs) in the literature. These improvements have been made by exploring new designs in simulations and studying some limited HEV prototype work. However, the common notions of HEV technology are greatly simplified interpretations of a technology that is still in its early stages of development. Current HEV technology offers the vehicle designer many new variables to consider in optimizing vehicle design. Trade-offs in powertrain designs and energy storage configurations do not lay in one-dimensional spectrums, but can be two or three dimensional. In this environment, designers must be very specific about their requirements before they can begin to design and optimize an HEV.

An HEV design can satisfy very different types of operational objectives. The design can offer a way to extend the range of an electric vehicle, to directly replace a conventional vehicle, or to blend of the attributes from either type. Within each of these primary operational categories are an infinite range of choices that relate to the hybrid component sizing. Added to these choices are complex power and energy control strategies that make the design and proper characterization of an HEV a very involved process. This paper will discuss these design choices in light of their ability to achieve intended vehicle mission objectives.

\section{DEFINITIONS AND COMMON TYPES OF HEVS}

There are two fundamental configurations of hybrid vehicles, series and parallel, that must be defined before we discuss the details of HEV design. The series HEV uses the electric motor as the sole source of motive power; the engine is coupled to a generator to provide charge to the batteries when desired. In a parallel HEV, both the engine and the electric motor provide motive power to the wheels.

Typically HEV designs have been separated into different types on the basis of their usage and operational capabilities. Although only three types of HEVs are commonly identified, the range of designs offer an unlimited number of potential HEV configurations are possible; many of these may offer a useful alternative to today's conventional vehicles. This section describes the three common HEV types.

RANGE EXTENDER - The range-extender HEV overcomes the limitations of current electric vehicle (EV) technology by enabling the hybrid to drive beyond its electric-only range. The range-extender hybrid is equipped with a large battery pack and a small engine that provides supplemental power to allow the vehicle to continue driving beyond the range of the battery, but at a reduced average power level. The small engine is packaged to allow the maximum utilization of the vehicle for electric-powered operation. This design is most conducive to a series. HEV configuration, with a small 


\section{DISCLAIMER}

This report was prepared as an account of work sponsored by an agency of the United States Government. Neither the United States Government nor any agency thereof, nor any of their employees, makes any warranty, express or implied, or assumes any legal liability or responsibility for the accuracy, completeness, or usefulness of any information, apparatus, product, or process disclosed, or represents that its use would not infringe privately owned rights. Reference herein to any specific commercial product, process, or service by trade name, trademark, manufacturer, or otherwise does not necessarily constitute or imply its endorsement, recommendation, or favoring by the United States Government or any agency thereof. The views and opinions of authors expressed herein do not necessarily state or reflect those of the United States Government or any agency thereof. 


\section{DISCLAIMER}

Portions of this document may be illegible in electronic image products. Images are produced from the best available original document. 
engine/generator set powering a large battery pack. However, as we show later, a parallel HEV with components of a similar size can achieve the same results.

The range-extender engine is sized smaller than what would be needed to satisfy the average driving power levels. An engine that provides $5-20 \mathrm{~kW}$ is sufficient to power the hybrid vehicle in light city traffic or at reduced speeds invoked when the batteries are nearing the end of their charge thus allowing the vehicle to return home or reach a charging facility. This design will fail to maintain battery state-of-charge (SOC) under all conceivable driving requirements [1] and would be described as a charge-depleting HEV.

FUELED ENGINE-ELECTRIC - This hybrid type, sometimes called the power-assist, is on the other end of the hybrid spectrum from the range-extender in terms of its operational mission and capabilities. The term fueled engine-electric is more accurate to describe this type of HEV. "Power assist" implies a parallel configuration, which is not the only possibility for this HEV type. The vehicle uses an electric propulsion system to augment the engine for improved fuel economy and decreased emissions. This HEV will rely on electrical energy produced on-board, eliminating the need to use the grid as an energy source. The vehicle has a moderately sized engine to provide the average power needed for all driving conditions. This vehicle type appears to be the leading candidate in the attempt to achieve the Partnership for the Next Generation Vehicle (PNGV) goals of three times the fuel economy of today's vehicles.

DUAL MODE - This hybrid vehicle type has attributes of both of the two other hybrid types. This HEV has the capability of electric only operation and has a battery pack large enough to drive a significant ZEV distance when it is preferred, but can use an engine that is large enough to provide power under all driving conditions when the ZEV range is exhausted. This enables it to do everything that conventional vehicles can with the addition of ZEV capability.

Distinguishing among these HEV types depend on the vehicle's desired primary mission. The range-extender is favored when the primary desired operation of the vehicle is similar to an EV -- an urban commuter vehicle with the ability to go beyond the electric-only range. The fueled engine-electric HEV can be a direct replacement for today's conventional vehicles, with the added benefits of reduced emissions and fuel consumption. This design is very attractive because it represents the most direct path to production if costs can be controlled. The dual-mode HEV has a great deal of flexibility; the vehicle can be charged every night and operate like an EV some of the time, but can also be used for long trips without regard to battery limitations or charging requirements. The disadvantage of this hybrid type is that the vehicle needs to simultaneously carry two large powertrains with their appropriate energy sources -- a definite weight and cost penalty compared with other HEV designs.
ENGINE AND BATTERY SIZING OF THE COMMON HEV TYPES - The three common types of HEVs can be identified by examining the sizing of the engine and battery components. Figure 1 is a graph typically used to illustrate the regions of component sizing that can define each HEV type. While the boundaries drawn between the hybrid types are somewhat arbitrary, HEVs with engines that produce less than $20 \mathrm{~kW}$ are characteristic of range-extenders. The engine in a fueled engine-electric design would likely be smaller than in a conventional vehicle in terms of peak power capability; around $20-80 \mathrm{~kW}$.

A battery pack that has less than $10 \mathrm{kWh}$ would allow fewer than 30 miles of ZEV range, which is considered less than practical for a vehicle intended to frequently operate like a ZEV. The dual-mode fits in the region between the other two component sizing schemes.

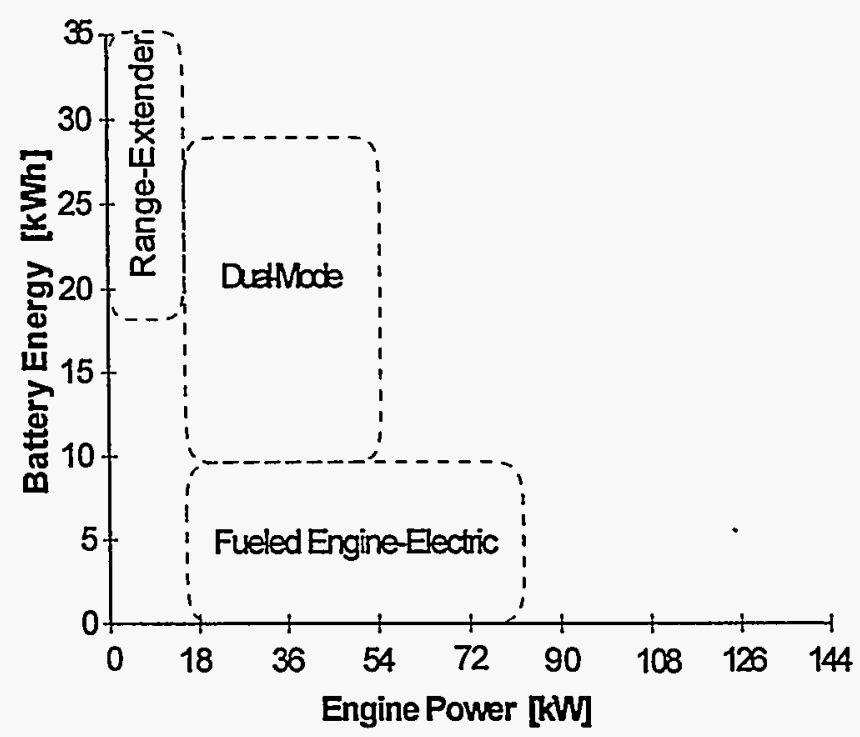

Figure 1: Component Sizing and Hybrid Vehicle Type

COMPONENT SIZING DESIGN OPTIONS IN 3-D - The design space can also be expressed in three dimensions to derive more detail about design tradeoffs in the hybrid vehicle [2]. There are three primary design features of the HEV: the engine, electric motor, and battery. Their respective sizing can be shown in terms of a design space, see Figure 2. The capability to power the vehicle with an engine is shown on the ' $x$ '-axis, and with an electric motor shown on the ' $y$ '-axis; the amount of energy that can be stored in the battery is shown on the ' $z$ '-axis. The electric vehicle and conventional vehicle are located at opposite corners of this design space cube. The EV, located in the far left upper corner of the cube, is fully capable with the electric motor, is equipped with a large battery pack, but has no engine to supplement the electric drive. The internal combustion engine vehicle (ICEV), located in the near right lower corner of the cube, is fully capable with the engine but has no electric drive system or battery energy storage capacity. An HEV that has acceptable performance in the electric-only mode (ZEV capable) lies on the top plane. An HEV that can be driven with acceptable performance powered only by the engine lies on the right-hand side plane. 


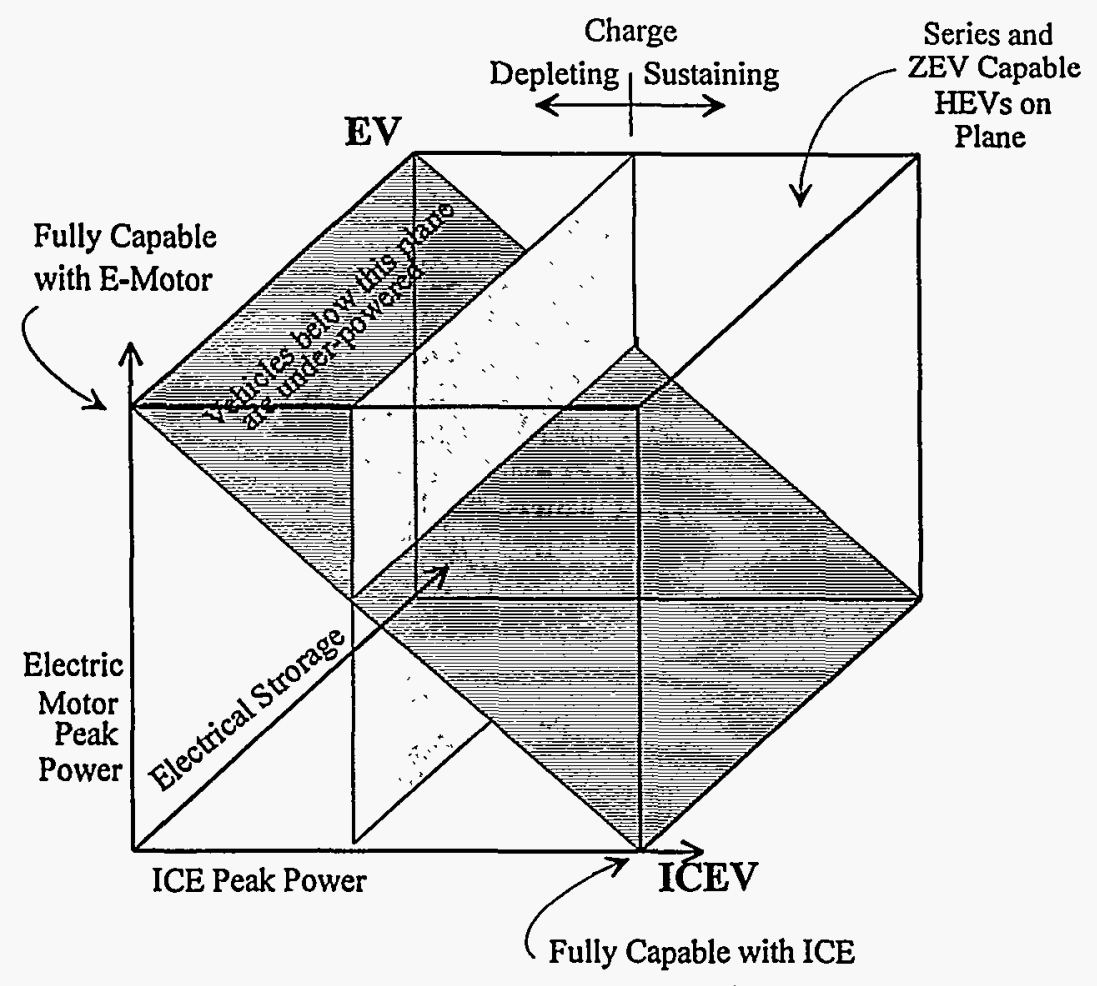

Figure 2: HEV Component Sizing Cube [1]

Because all motive power is supplied by the electric drive system, it must be sized large enough to give acceptable vehicle performance. Thus all series HEVs should occupy the top plane of the cube. Parallel HEVs can be found anywhere within the cube; however, because the engine and electric motor together must provide sufficient total acceleration power, a practical parallel HEV must be located above the diagonal plane shown in the cube [3].

Regardless of the configuration (i.e., series or parallel), the engine must be able to provide power at a higher rate than the average power required to drive the vehicle. If the engine is too small, the vehicle must use battery energy to maintain the power requirements; this is a charge-depleting HEV design. The vertical plane in Figure 2 illustrates the transition between charge-sustaining and charge-depleting designs. The actual power level of the engine where this transition occurs depends upon the design of the hybrid system, the driving cycle, and the vehicle road load on a given cycle.

\section{DETAILED CLASSIFICATION OF HEVs}

The common HEV types described earlier (range-extender, dual-mode, fueled engine-electric) are starting points for HEV classification. The classification process involves identifying vehicle parameters that are fundamental design choices, configurations, and operational characteristics. Table 1 lists vehicle design parameters that classify HEVs in a much greater level of detail than the three basic HEV types.

There are basically four parameters that identify an $\mathrm{HEV}$ with sufficient detail to describe the vehicle's attributes and characteristics. The series and parallel configuration is a straightforward design choice. The engine size, the ability to charge on-board, and the charging strategy all contribute to the issue of charge sustainability. This major design parameter affects how the vehicle can be operated with respect to vehicle range and off-board charging requirements. The peak power of the electric propulsion system will determine the ability to drive the vehicle in ZEV mode. The battery capacity will determine the ZEV range but if the designer does not wish to charge off-board, the battery pack would be small and optimized for power requirements instead of energy storage.

\section{OPERATIONAL NATURE AND ENERGY MANAGEMENT STRATEGY}

The energy control strategy of a fueled engine-electric, charge-sustaining HEV (an HEV that does not charge from the grid) is not as complicated as the strategies for HEV types that use significant off-board electrical energy. This vehicle is only using one off-board source of fuel constantly maintaining the battery charge. The fueled engine-electric HEV may react

Table 1: Detailed HEV Classification

\begin{tabular}{|r|c|c|c|c|}
\hline Parameter & \multicolumn{2}{|c|}{ Choices } & Notes \\
\hline Configuration & Series & Parallel & $\begin{array}{r}\text { HEVs are usually only one or the other, some prototypes have demonstrated the } \\
\text { ability to switch between series and parallel. }\end{array}$ \\
$\begin{array}{r}\text { On Board } \\
\text { Capability }\end{array}$ & $\begin{array}{c}\text { Charge- } \\
\text { Sustaining }\end{array}$ & $\begin{array}{c}\text { Charge- } \\
\text { Depleting }\end{array}$ & $\begin{array}{c}\text { A charge-sustaining HEV has the capability to deplete or sustain charge, a } \\
\text { charge-depleting HEV is always depleting. The transition between sustaining and } \\
\text { depleting depends upon the average power requirements of the driving cycle and the } \\
\text { capabilities of the on-board charging system. An HEV is classified as } \\
\text { charge-sustaining if it can maintain SOC under most any driving condition. }\end{array}$ \\
\hline $\begin{array}{r}\text { Electric } \\
\text { Propulsion Power }\end{array}$ & $\begin{array}{c}\text { ZEV- } \\
\text { Capable }\end{array}$ & $\begin{array}{c}\text { ZEV- } \\
\text { Incapable }\end{array}$ & $\begin{array}{c}\text { A ZEV-capable vehicle is one that can maintain acceptable vehicle acceleration rates } \\
\text { using its electric drivetrain only; this depends upon the electric motor peak power and } \\
\text { a particular trip's acceleration requirements. }\end{array}$ \\
\hline Battery Capacity & $\begin{array}{c}\text { Sufficient for } \\
\text { Off-Board } \\
\text { Charging }\end{array}$ & $\begin{array}{c}\text { In-Sufficient for } \\
\text { Off-Board } \\
\text { Charging }\end{array}$ & $\begin{array}{c}\text { The capacity at which off-board charging is practical is slightly arbitrary, but battery } \\
\text { systems will either be chosen with either power or energy requirements in mind } \\
\text { because if the vehicle was not intended to charge off-board, then battery } \\
\text { capacity will be reduced to a minimum to conserve vehicle weight. }\end{array}$ \\
\hline
\end{tabular}


to variations in driving patterns, but the battery SOC will stay within a particular range (e.g., from 50-80\%) during operation. We can assume that the fueled engine-electric HEV operates only in a single charge-sustaining mode that does not change with respect to net usage of electrical battery energy.

However, an HEV that is designed to charge from the grid offers flexibility in how the two on-board energy sources are utilized to meet day-to-day driving needs. Operational issues (e.g., like off-board charging requirements and their frequency, the amount of ZEV range and when it can be used, vehicle range before a reduced power mode is reached, and controlling on/off engine operation) can be determined by the hybrid component sizing and configuration (as discussed earlier) and the management strategy of the vehicle's energy inventory formulated by the HEV designer.

The energy management strategy can take the form of a very active algorithm that is continually updating the operation of the vehicle on the basis of the driving needs. The strategy can also be broken down into discrete energy management modes that are automatically engaged or manually selected by the driver.

ENERGY MANAGEMENT OBJECTIVES - In the case of an HEV that charges from the grid, one of the primary objectives of the energy management strategy is to use as much off-board electrical energy as possible during the life of the vehicle. The societal benefits of this type of operation are reduced emissions and petroleum usage over the vehicle's lifetime.

If an HEV is charged primarily at home overnight, even modest ZEV ranges can displace a significant percentage of engine-driven miles. This grid-connected HEV has been shown to have the potential to displace more engine-driven miles than EVs with the same $\mathrm{ZEV}$ range because required trips that are beyond the range of the EV must be made using a conventional vehicle; however, these trips can be made by an HEV that has some ZEV capability [4]. Data on the distribution of daily vehicle miles traveled (VMT), obtained from driving surveys, are used to calculate the number of displaced engine-driven miles with use of EVs and HEVs. Using the Nation-wide Personal Transportation Survey (NPTS) data for California, the percentage of displaced combustion engine VMT was calculated for EVs and HEVs on the basis of their respective $\mathrm{ZEV}$ ranges [5].

Table 1: Engine VMT Displaced by ZEV Operation of HEVs and EVs

\begin{tabular}{|c|c|c|}
\hline $\begin{array}{c}\text { Electric Range } \\
\text { (miles) }\end{array}$ & HEV & EV \\
\hline 10 & $24.3 \%$ & $3.0 \%$ \\
\hline 20 & $42.1 \%$ & $9.9 \%$ \\
\hline 30 & $55.2 \%$ & $20.4 \%$ \\
\hline 40 & $65.0 \%$ & $29.9 \%$ \\
\hline 50 & $72.2 \%$ & $39.2 \%$ \\
\hline 60 & $77.7 \%$ & $47.6 \%$ \\
\hline 70 & $81.5 \%$ & $57.2 \%$ \\
\hline 80 & $845 \%$ & $63.1 \%$ \\
\hline 90 & $86.6 \%$ & $67.3 \%$ \\
\hline
\end{tabular}

USE OF OPERATIONAL MODES - As stated earlier, operational modes are elements of the energy management strategy. An HEV can have many different HEV modes plus other modes for dedicated ZEV operation. Examples of some operational modes are engine-on mode, engine-only mode, ZEV-mode, charge-depleting mode, charge-sustaining mode, charge-recovery mode, and low-power mode; plus many others.

Charge-sustaining or charge-depleting modes must not be confused with HEVs that are charge-sustaining or charge-depleting by design. A charge-sustaining HEV can operate in a charge-depleting mode when desired. However, a charge-depleting HEV cannot operate in a charge-sustaining mode unless the driving power demands are reduced.

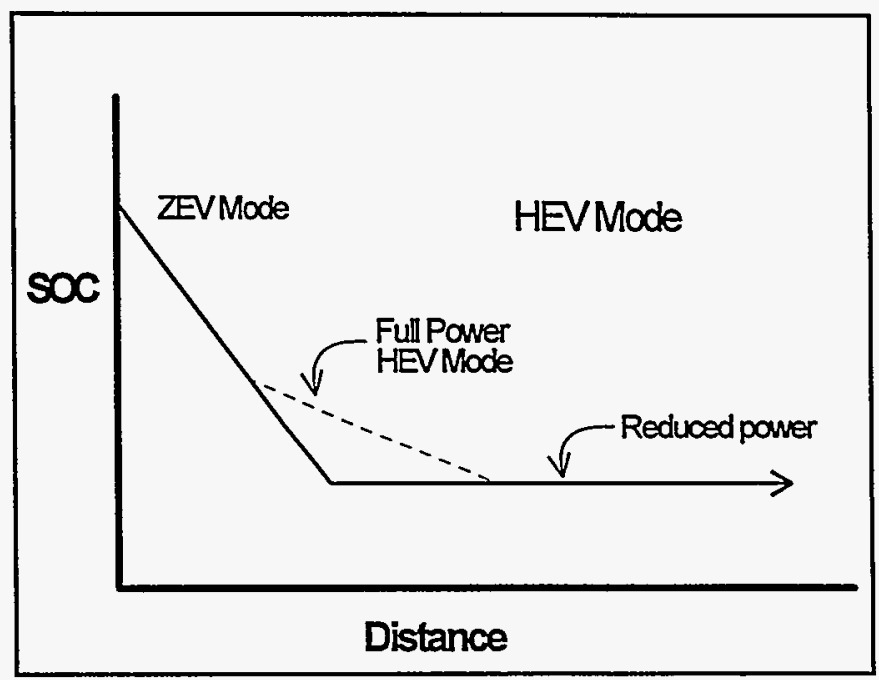

Figure 3: Charge Depleting HEV

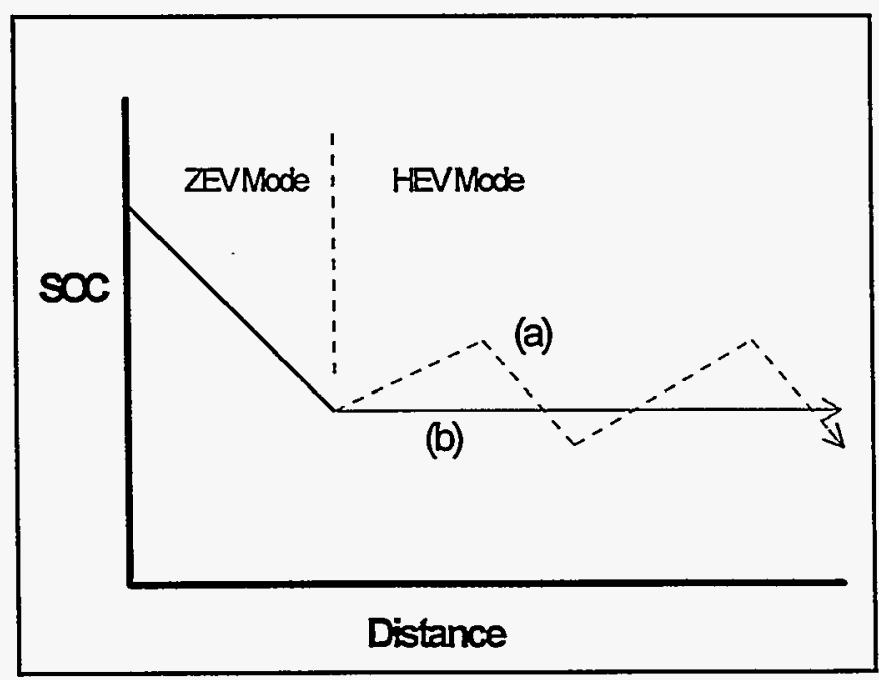

Figure 4: Dual-Mode HEV

Charge-Depleting HEVs - Figure 3 shows two examples of energy management strategies for a charge-depleting range-extender HEV. Because it will deplete the batteries in any mode, eventually the vehicle will switch to a reduced power mode. The dashed line in the graph indicates a switch from ZEV mode to a charge-depleting, full-power HEV mode. The point at which the vehicle switches from ZEV to HEV 
operation can be adjusted (to avoid reduced power situations) by sacrificing some ZEV range for that trip. By knowing the distance that will be traveled before the next charge, the driver can find a transition point between ZEV and HEV operation, making it possible to use the maximum amount of electrical energy as possible without prematurely depleting the batteries.

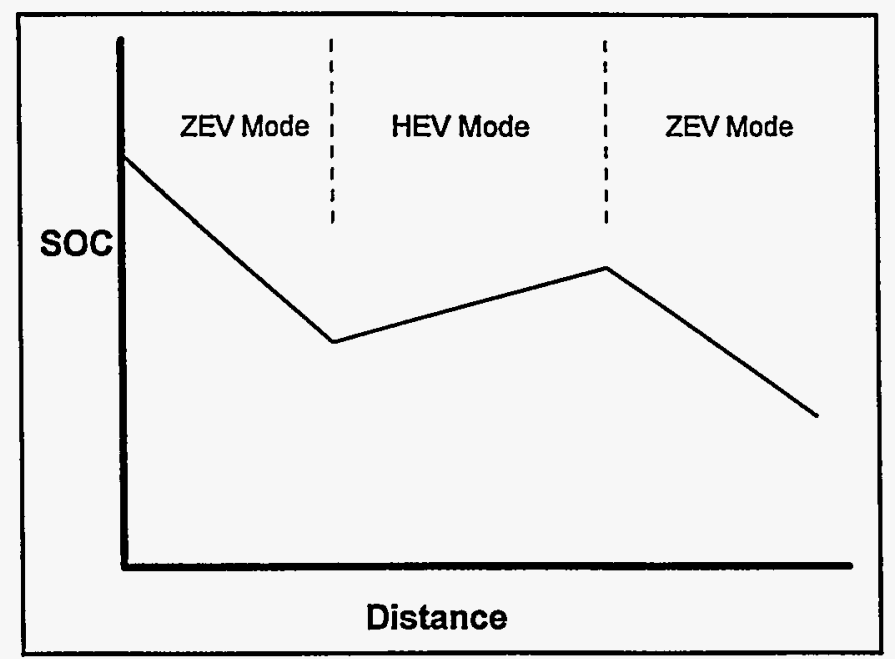

Figure 5: Manual Control Over Operational Modes, A Trip Out of And Back to the City

Charge-Sustaining Dual-Mode HEV - The classic dual-mode HEV, switches from ZEV-mode to HEV operation when the batteries are nearly depleted. The ZEV range is defined as the lowest SOC at which the batteries maintain minimum power for normal operation. When this point is reached the engine is used to provide the energy to continue to drive.

Figure 4 shows two lines as possible power control strategies that will be discussed later. Line (a) shows the SOC rising and falling between set-points, and line (b) shows the SOC when the engine is operated to better match the road load, avoiding large sways in battery SOC.

Because the dual-mode HEV has the flexibility to be charge-sustaining at any time, operational modes could be selected to further reduce emissions in urban areas. For example, the driver may set the vehicle's operational mode on the basis of the vehicle's geographical location in order to reduce urban emissions. Advancements in low-cost global positions sensors (GPS) may allow automatic mode selection based upon geographic location. Figure 5 is an example of how various modes can be mixed to control ZEV mode operation for reduced vehicle emissions in urban areas.

\section{HEV POWER CONTROL STRATEGIES}

While the energy management strategy directs the use of the on-board energy sources, the power control strategy involves the details of how the electric motor, engine, transmission, and the other related vehicle components propel the vehicle. The goal is to efficiently fulfill the highly variable driving power requirements and still meet the objectives of the energy management strategy. For example, if the vehicle is in a charge-sustaining mode, the power control strategy would be to use more engine power to maintain the SOC. The power control strategy must be operated by some process, either a passive open-loop control system, or, preferably, an active closed-loop control computer. The key to achieving an HEV's potential efficiency gains is the ability of the power control strategy to operate the hybrid components to achieve the highest overall system efficiency.

The power control strategies for series and parallel HEV configurations must be discussed separately because of their fundamental differences.

PARALLEL HEV POWER CONTROL STRATEGIES Recent advances in the efficiency of electric drive systems and computer controls have given HEV designers added flexibility in parallel power control strategies. A new generation of highly efficient Brushless DC and AC Induction motors have precise torque control and are able to add or subtract torque thus subtracting or adding charge to the batteries to meet the objectives of the power control strategy.

The primary role of an electric motor in a parallel HEV is to augment the engine by either providing power during peak demand or by load leveling the engine. In a power peaking strategy, the electric motor provides power when the demand for acceleration is beyond the capabilities of the engine. If there are no provisions for on-board charging, the vehicle is always charge-depleting.

With load leveling, the engine can be operated in highefficiency regions with reduced load transients when the electric motor is properly used during hard accelerations, and used to take off power to recharge the batteries, avoiding inefficient low-load conditions.

However, when optimizing the power control strategy for an HEV design, the combined inefficiencies of the engine and the electric drivetrain losses (i.e., losses from the batteries, the electric motor and its controller) must be considered to achieve the best vehicle efficiency [5]. The engine experiences inefficiencies during particular speeds and load conditions and the battery system experiences losses during high rates of charge and discharge. The power control strategy can trade off power between the electric drive and engine operation in a way that optimizes the engine and the electric drive together in the most efficient combined operation.

Engine Control Based On Speed - One parallel HEV power control strategy involves the application of the electric motor during hybrid operation on the basis of vehicle speed. The vehicle is driven as a ZEV in low-speed, urban traffic, but above a chosen speed, the engine is automatically engaged to provide motive power. The advantage of this design that the typically inefficient demands on the engine during low-speed travel are avoided. When the road power requirements are more conducive to efficient engine operation, the engine is prevents rapid charge losses associated with driving in ZEV mode at higher speeds.

Engine Control Based On Vehicle Power Demands - The position of the acceleration pedal may be used to control engine use. In one power peaking strategy, as the accelerator pedal is depressed, the motor torque is increased until its maximum power is reached; then the engine is employed to provide the added power needed to keep up with the acceleration demands. In another strategy, as the acceleration 


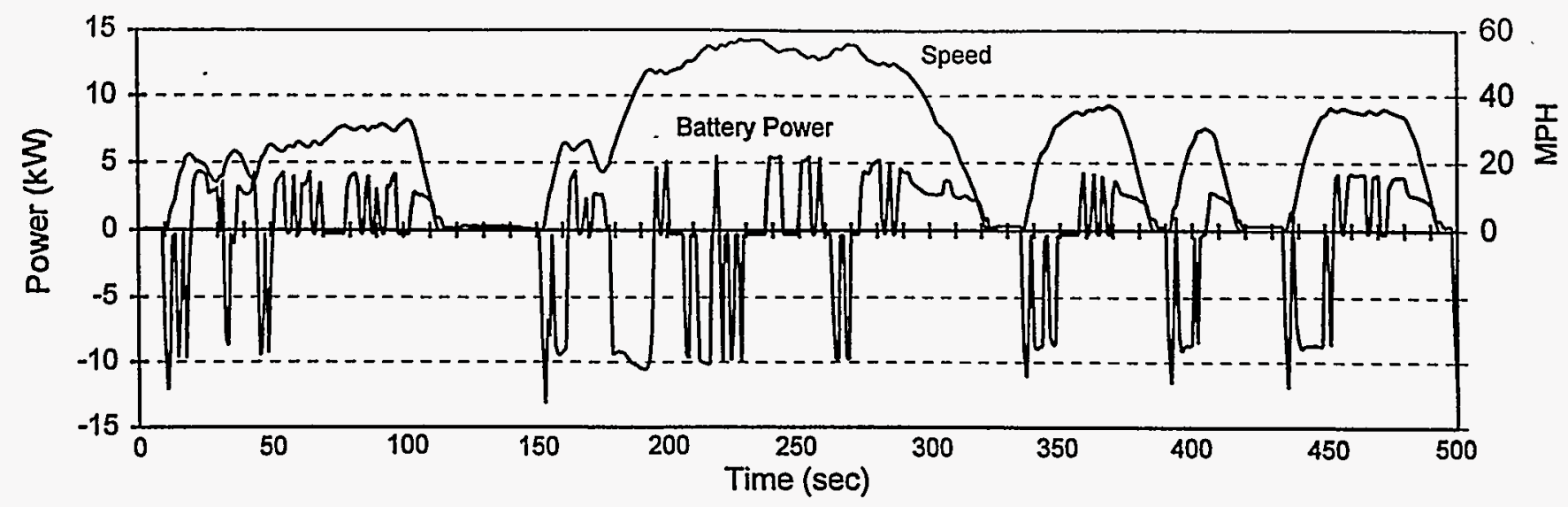

Figure 6: Data From a Load Leveling Parallel HEV During First 505 s of FTP Test.

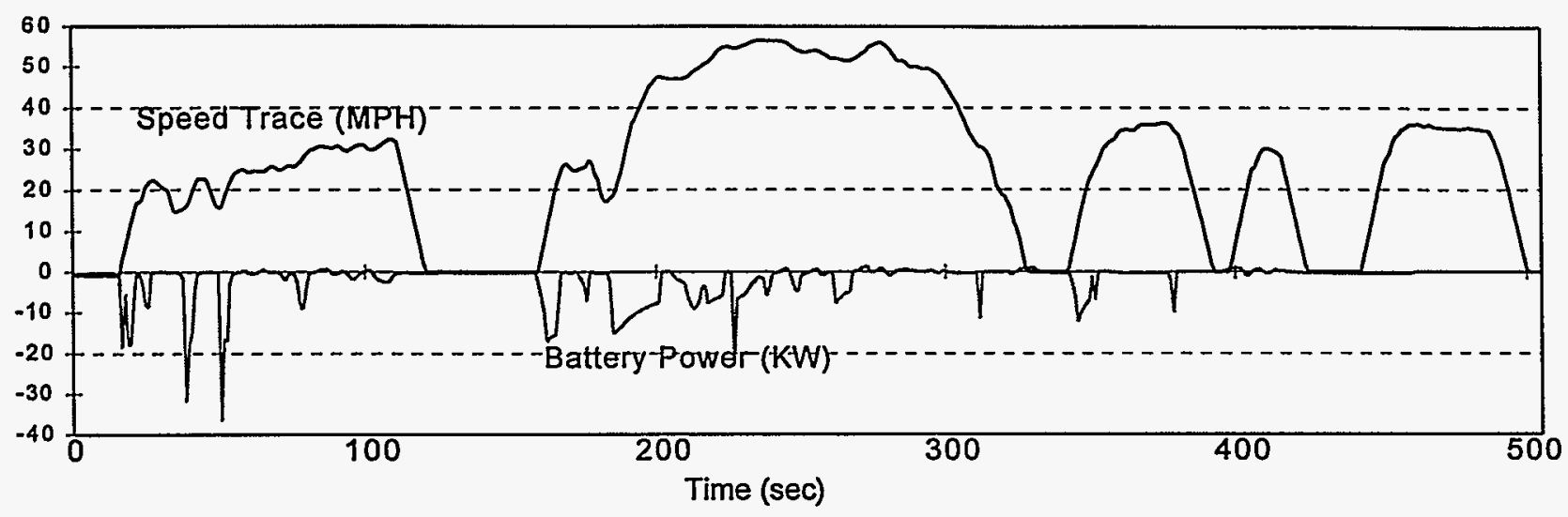

Figure 7: Data From a Power Peaking Parallel HEV During First $505 \mathrm{~s}$ of FTP Test.

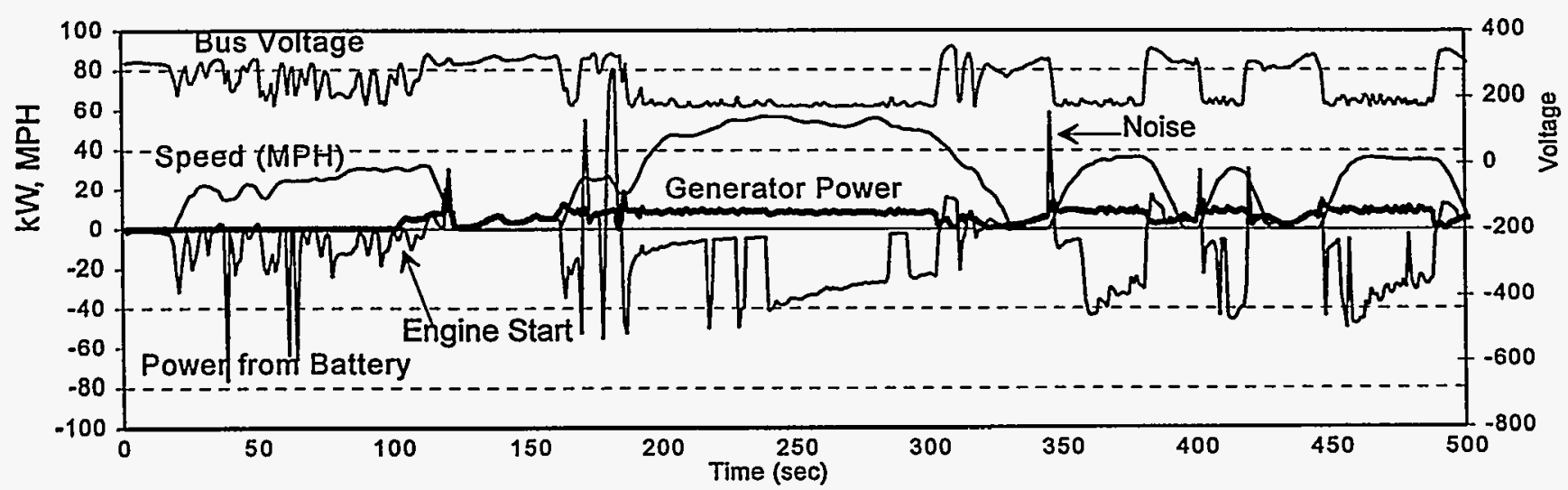

Figure 8: Data From a Series HEV With Thermostat and Engine Follower Charecteristics During First 505 s of FTP Test.

pedal is depressed, both the engine and electric motor power are increased together. These strategies can also be blended for the best use of both the engine and motor.

Detailed Look at a Load Leveling Power Control Strategy- A time trace of the University of Maryland's entry in the 1994 HEV Challenge is shown in Figure 6. The data were acquired from the first 505 seconds of a Federal Test Procedure (FTP) dynamometer test in the emissions event of the competition. This vehicle is a fueled engine-electric, charge-sustaining, parallel HEV with a load-leveling power control strategy. Notice the dynamic nature of the team's power control strategy that adds and subtracts torque based upon the driving demands. As part of the control strategy, the team used a multi-dimentional look-up table that kept the engine in the most efficient load and speed regions. Not only did the algorithm control the electric motor torque in load leveling the engine, but the transmission was a continually variable transmission (CVT) that was controlled by the main hybrid computer to actively adjust transmission ratios.

Detailed Look at a Power-Peaking HEV Control - Figure 7 is another look at the data from the first 505 seconds of the FTP test of the Illinois Institute of Technology HEV that is using the power peaking control strategy. The power taken by the electric propulsion system is seen at the beginning of the 
harder accelerations and during periods of acceleration at higher speeds (during "hill" two).

SERIES HEV POWER CONTROL STRATEGIES - The advantage of the series HEV configuration over the parallel configuration is that the engine can be operated independently of the vehicle speed and acceleration demands. But, as in the parallel configuration, to optimize the power control strategy, designers must consider the combined operational efficiencies of the batteries, the electric drive system, the engine, and (in the case of a series HEV) the electric generator.

Two power control strategies represent the extremes in the power control design spectrum for series HEVs: they are the "thermostat" control mode and the "engine follower" control mode [7]. The thermostat control strategy allows the engine to generate power at a set level until the SOC rises above a particular level. Then the engine is turned off and the vehicle is essentially driven as a ZEV. When the SOC has fallen below the minimum SOC point, the engine is turned back on -- similar to the temperature control of a home furnace. In contrast, the engine follower mode forces the engine to follow the road load demands within its designed power limits, so the engine always remains on.

Between these two extremes lies the optimum point where the road load transients are balanced between the engine and the battery system, keeping the combined efficiencies of both systems at their highest. The optimum point depends on the range of efficient engine operation and the in/out battery system efficiency. If the range of efficient engine operation is broadened or the battery efficiency is reduced, the optimum power strategy will move in the direction of the follower mode. Conversely, if the engine has a very narrow operational window or the battery efficiency is increased, the optimum strategy will more closely resemble the thermostat mode.

The power control strategy for the series HEVs at the competitions were not optimized between the follower mode and the thermostat mode to achieve the greatest efficiency, but the dynamics of an electrical charging system can, in some cases, act like the engine follower mode. If the series generator was designed to operate at constant bus voltage connected to the main bus voltage, the current taken out of the generator would be affected by the circuit impedance. During high power demands from the electric motor, the circuit impedance would drop, causing the generator current to increase and the load on the engine to increase (see Figure 8). Notice in Figure 8 that while the vehicle is using the motor, the voltage drops and the generator power increases. During decelerations and at rest, the generator power drops near zero. In this instance, like some of the simplistic parallel control strategies, an advanced computer control system would greatly benefit the HEV designs in terms of fuel utilization.

\section{LESSONS IN HEV DESIGN: THE HEV CHALLENGE}

INTRODUCTION - In the 1994 and 1995 Hybrid Electric Vehicle (HEV) Challenges, and in the 1995 U.S. Department of Energy (DOE) Advanced Student Hybrid event, sponsored by DOE and a host of industry partners, over
50 prototype HEVs were built by North American university and college student teams. These engineering competitions were designed to evaluate the vehicles' performance, acceleration, design, emissions, fuel economy, and endurance. Besides offering a valuable learning experience for the students, these unique competitions allowed examination of a large number of prototype HEVs, all with radically different design approaches. One important aspect of this competition series is that students are not necessarily influenced by conventional ideas concerning HEV designs. In fact, many design configurations and control strategies used by the teams opened doors to understanding HEV types not previously considered.

These vehicles offer a real look into the operation of different designs. The entire fleet, examined as a whole, show trends that reflect the availability of current technology. Because many are radically different in design, they offer an opportunity to sharpen the focus of HEV classification.

\section{HEV CHALLENGE VEHICLE DESIGNS}

The following teams participating in HEV competitions were selected for their noteworthy designs. The teams are numbered 1 through 6 for reference. The Appendix provides a table with a larger selection of HEV competition vehicles; the table includes their design specifications and performance results.

(1) University of Maryland- This parallel, ZEV-incapable, charge-sustaining HEV with insignificant battery storage capacity, performed well in fuel economy in 1994. The Saturn drive train was replaced with a small $44-\mathrm{kW}$ (60-hp) 1.0-liter engine with a $18.7-\mathrm{kW}$ electric motor that load-leveled the engine buy adding and subtracting power. The vehicle is operated with the engine always on, and the nickel-cadmium battery pack was used for its high power density (large energy storage capacity was not desired in this design). Despite the added weight of the HEV system, the vehicle achieved a better-than-stock fuel economy results with 16.9 gasoline equivalent $\mathrm{km} / \mathrm{L}$ (39.8 MPG) using M85 methanol fuel ( $85 \%$ methanol, $15 \%$ gasoline) on the FTP cycle.

(2) University of California, Davis - This HEV represents one of the designs that does not fit typical hybrid vehicle notions. This engine-assist $\mathrm{HEV}$ is a parallel, charge-depleting (marginally), ZEV-capable HEV with significant battery storage capacity. Although it is a parallel configuration, looking only at the component sizing, it appears to be a range-extender series HEV. The engine is a small 0.57-L, 13.4-kW (18-hp), 2-cylinder engine. The electric motor is a large $44-\mathrm{kW}$ brushless DC. Both are coupled together on the input side of a 5-speed transaxle:

Like a range-extender, the primary vehicle mode is ZEV. The large battery pack can meet daily city driving needs, and when the vehicle needs to be taken beyond its ZEV range, the small engine can be engaged for a long trip.

This vehicle's energy management strategies focus on reduced emissions and maximum use of electrical energy. The electric motor charges the batteries by regenerative braking, but the batteries are never charged from the engine. The philosophy is that all electrical energy used comes from 
the grid. In this way, the engine is used as little as possible.

In one of its passive energy management strategies, the vehicle can engage the engine during higher-speed operation and during high power demands. As the batteries are depleted, the engine is engaged more and more frequently, until it is used for all power requirements. This blending of the ZEV and HEV modes is more sophisticated than other (typically series HEV) approaches that use a particular battery SOC setpoint to engage the engine for increased range.

This unique parallel HEV design has an advantage over a series HEV with similarly sized components because there is no need for a generator in a parallel design. In addition, for highway driving, the engine efficiency can be as high or higher than a series HEV because a parallel design does not experience the efficiency losses associated with converting power from an engine into electrical power, then back to mechanical power.

(3) University of Tennessee - Unlike the Maryland HEV design that load-levels the engine during hard accelerations and transients, the Tennessee design uses the electric motor essentially for power-peaking the undersized engine. The engine is the same 1.0-L engine model used in the Maryland design, but it has been modified for use with natural gas. The electric motor is a $32-\mathrm{kW}$ brushless DC that is used during high power demands that the engine cannot fully handle. The electric motor engages for only 2-3 seconds during the beginning of the acceleration events, providing $20-30 \mathrm{~kW}$ of power. The (gasoline equivalent) fuel economy results were slightly worse than stock, with $9.8 \mathrm{~km} / \mathrm{L}(23 \mathrm{mpg})$ compared to the stock rate of $12.3 \mathrm{~km} / \mathrm{L}(29 \mathrm{mpg})$, however, the emissions rates were lower than the California ultra-low emissions vehicle (ULEV) rates.

The amount of energy depleted during the accelerations is small and is almost completely resupplied during regenerative braking. One novel feature used by Tennessee and a few other schools: the engine does not use an alternator, but draws power from a $\mathrm{DC} / \mathrm{DC}$ converter off the main battery pack to supply an undersized $12-\mathrm{V}$ accessory battery.

(4) Western Washington University- The energy management strategy of this vehicle is similar to that of the UC Davis vehicle. This HEV is classified as a parallel, charge-sustaining, ZEV-capable, vehicle with significant electrical energy storage. A modified stock engine was used with a $32-\mathrm{kW}$ electric motor. The accelerator pedal gives input to both the engine throttle and the motor controller. A simple control mechanism engages the engine when the batteries can not provide enough power to match the level associated with the pedal position. The engine is quickly started at a particular level of pedal depression; further depression gradually opens the throttle. When the batteries are charged, the vehicle can be driven normally without depressing the accelerator pedal far enough to engage the engine. But as the battery SOC drops, the accelerator pedal is depressed more to achieve the desired power until eventually, when the batteries are dead, the engine works full time to power the vehicle.

This control strategy, though robust, is not as sophisticated as a fully active computer control that provides optimal use of the hybrid components. Most HEV designs were controlled using a simple control; these vehicles were operated successfully, but had limited success in demonstrating high vehicle efficiency.

(5) California State University, Chice - This chargesustaining, series, ZEV-capable HEV with significant electrical energy storage capacity had an enormous $31-\mathrm{kWh}$ nickel-metal-hydride battery pack and a powerful $150-\mathrm{kW}$ (200-hp) electric motor. This HEV uses the thermostat power control strategy.

The vehicle achieved a SOC corrected $13.8-\mathrm{km} / \mathrm{L}$ (32.4-mpg) result on the FTP test (a stock Saturn gets 12.3 $\mathrm{km} / \mathrm{L}$ ). Not only is the fuel efficiency impressive, but this vehicle has an estimated $240-\mathrm{km}$ ZEV range and the power to accelerate significantly faster than the stock Saturn.

(6) University of West Virginia - This vehicle, like that designed by the CSU Chico team, is a dual-mode HEV with an on/off engine control strategy. However, this team took a very direct, relatively low-cost approach that produced very good results in 1994. This series, charge-sustaining, ZEV-capable HEV, with significant battery storage capacity, used a relatively inexpensive 44-kW DC-type electric motor that does not have regenerative braking capabilities. The batteries were typical lead-acid type. In spite of the low-tech approach, the vehicle achieved a ZEV efficiency of 5.97 $\mathrm{mi} / \mathrm{kWh}$ (a result on the order of advanced-production EVs) and $20.4 \mathrm{~km} / \mathrm{L}$ (48.1 mpg) SOC-corrected fuel economy. The engine/generator was a $16.4-\mathrm{kW}$ (22-hp) 0.6-L Kawasaki 2-cylinder coupled to a Fisher alternator. The engine was operated at high-output for efficiency and produced slightly more charge than was used during the FTP emissions and fuel economy test. The high charge rate allowed the engine to be off during one third of the entire test cycle.

DESIGN SPACE - The designs of the participating vehicles in the HEV competitions can be shown within the design space cube shown in Figure 2. With these plots we can look at ZEV capability and range, estimated charge-sustainability, underpowered designs, the various HEV types, and overall design trends.

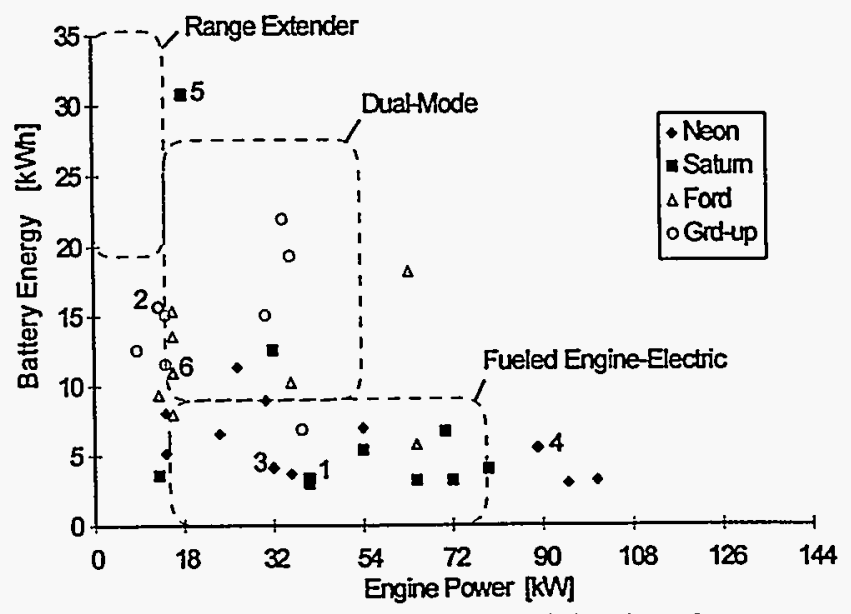

Figure 9: Engine and

Battery Sizing by . lass

Engine and Battery Sizing by Class - Figure 9 includes the battery energy vs. engine power axes of the cube (a top view). Boxed regions show the classic HEV types. Notice that, as a whole, the amount of battery storage was reasonably 
low. Only four vehicles possessed more than $17 \mathrm{kWh}$ of battery storage. The Ford and Ground-Up classes, as a whole, had greater energy storage and smaller engines. Most Saturns had very small battery energy storage, and the Neons were generally mixed. These design trends follow the Challenge requirements of vehicle types are that are listed in the legend; the Fords and Ground-Ups (shown as "Grd-up") were required to have 25 miles of ZEV range; the Saturns and Neons had only a 5-mile minimum. In addition, the Saturns are required to be charge-sustaining.

Engine and Battery Sizing by Configuration - Figure 9 shows how competition ZEV requirements affected the design; Figure 10 shows trends in design separated by their configuration. There were more parallel designs than series designs and the HEV types followed expected trends in configuration. Most fueled engine-electric HEVs are parallel. A few vehicles shown left of the dual mode and fueled engine-electric regions pushed the limit of small engine and battery system choices. It would be interesting to test these vehicles to find out whether their total vehicles range may be battery limited.

Engine and Electric Motor Sizing by Configuration Figure 11 is the front view of the HEV cube. Using this figure we can determine which system the motive power is coming from in each of the designs. We have arbitrarily chosen $54 \mathrm{~kW}$ as the edges of the HEV design cube (shown as a square in Figure 11) which is the minimum peak power needed to propel the vehicles with marginally acceptable performance. Line (a) is the upper plane in the HEV design cube. Six series HEVs appearing under line (a) are considered underpowered. They showed poor competition acceleration results (the estimated 0 to $60 \mathrm{mph}$ times were greater than 20 seconds). All parallel vehicles below line (a) are underpowered in ZEV mode (ZEV incapable); two parallel vehicles shown above line (a), can be classified as $Z E V$ capable.

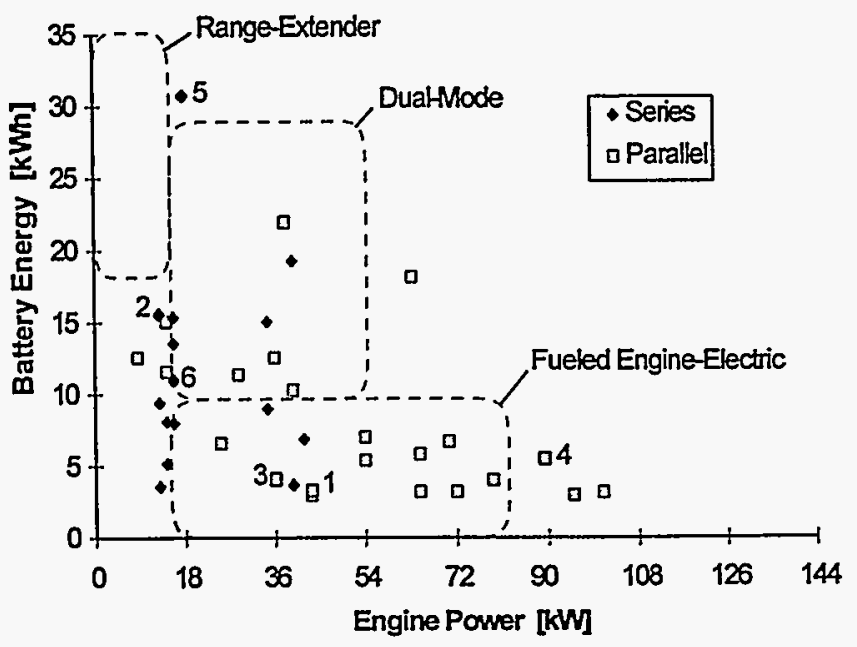

Figure 10: Engine and Battery Sizing by Configuration

Line (b) is the 54-kW engine and motor combined power output level, which applies only to parallel vehicles. All parallel designs appear above line (b), and thus have acceptable combined power. Nearly all the best acceleration results at the competitions were from parallel HEVs.

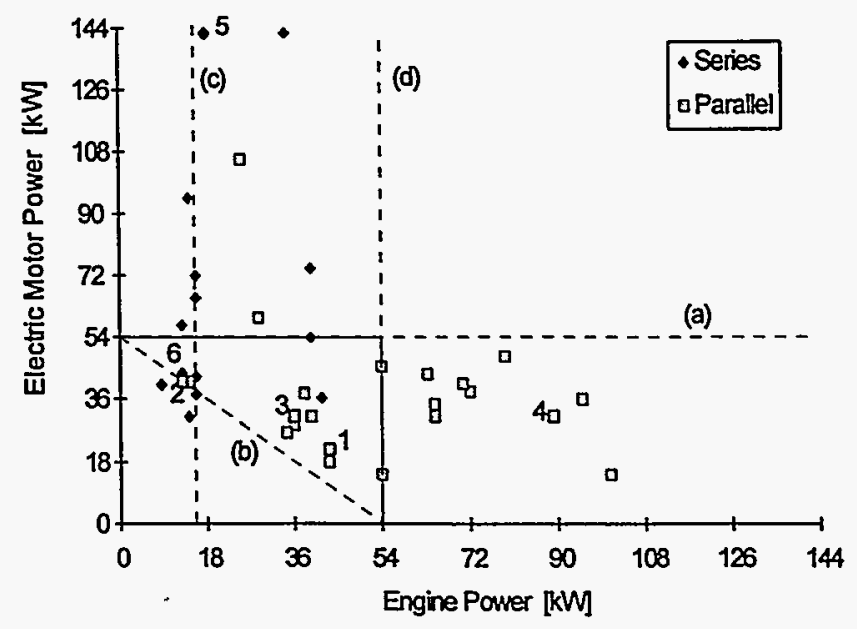
Figure 11: Engine and Electric Motor Sizing
by Configuration

Line (c) indicates an estimated transition from charge-sustaining to charge-depleting operation for series HEVs and parallel HEVs with on-board charging capability. Small engine choices caused a few series vehicles to have charge-depleting operation on the standard city test cycle, but a few parallel vehicles were also charge-depleting not as a result of engine size, but because the on-board charging systems were either underrated, under-utilized, or non-existent.

Line (d) is the right-hand plane in the design cube. If a parallel vehicle does not have the capability to charge on-board, it must appear to the right of line (d) to drive in a charge-sustaining mode (i.e., the engine-only mode).

CONFIGURATION TRADE-OFFS SEEN IN HEV RESULTS - The many vehicles tested in the HEV competitions prompt the question of which fundamental configuration offers the best overall performance. The teams placing highest over all three years of the competitions have had parallel configurations. However, this does not mean that the parallel configuration is inherently better. The best fuel economy results have been from series HEVs. There may not be a clear answer to the configuration question, but a few points can be made about their differences.

Although series vehicles have more components, they represent a more direct design approach than the parallel HEVs. Many teams opted for the series approach when considering the simple operating behavior of such a design. The series hybrid control strategy can be as simple as the engine on/off, thermostat control type. Such vehicles can (and have in 1994 and 1995) achieve better fuel efficiency than stock vehicles, despite the weight added in the conversion to an HEV.

The parallel HEV actually has one less component (the series generator) and can have a smaller electric motor than the series design because not all motive power must come from the motor (if ZEV-incapable). Parallel HEVs can utilize modern electric motors that can reverse the torque and recharge the batteries to maintain the battery's SOC, 
eliminating the need for a dedicated generator. This feature provides some weight and packaging advantages. But the key to achieving high fuel economy with good drivability is the control strategy. In order for a parallel HEV to load level the engine with the same efficiency as a series HEV, a highly advanced control strategy with sophisticated computer hardware must be developed that can operate the engine most efficiently.

\section{SUMMARY AND CONCLUSIONS}

HEVs offer: (1) increased flexibility in vehicle energy utilization and (2) the potential for improved energy economy and emissions control by exploiting the hybrid's higher level of operational complexity. The designer's choice in sizing each component and configuring the whole package will ultimately determine the capabilities of the vehicle. Issues concerning off-board charging, battery depletion rates, and vehicle range are affected by how the on-board energy sources are managed -- either by manual manipulation of operational modes or through passive energy management.

As shown by the HEV Challenge results the level of sophistication in the power control strategy is vital in achieving high vehicle efficiencies. Without sophisticated control and design optimization, the resulting design may produce emissions and fuel economy results that are actually worse than those from the stock vehicle.

Because of the large array of design choices available with HEVs, classification must be more sophisticated than describing only three basic HEV types. Although these hybrid types depend on the basic vehicle missions, to fully describe their operational potential requires knowledge of their configuration, component sizing and capacities, and energy management capacities.

This new level of complexity causes significant problems for future acceptance of HEV technology. Future testing procedures required for emissions regulation and EPA fuel economy estimations must accommodate the new complexity. Significant efforts are underway to develop HEV test procedures. However, with only prototype HEVs to validate the current procedures, it will be some time before a robust, accurate test procedure is developed and accepted. Consumers may need to be more technically aware to understand the new operational concepts inherent in HEVs, and control systems will need to be designed for ease of use if HEVs are to gain widespread acceptance in the marketplace.

\section{REFERENCES}

1. Burke, A.F., "Hybrid/Electric Vehicle Design Options and Evaluations," SAE Paper No. 920447, 1992.

2. Bates, B., "Getting a Ford HEV on the Road," IEEE Spectrum, July 1995.

3. Duoba, M., et al., "HEV Design Choices With Performance Results From HEV Design Events," Sustainable Transportation S/EV 95 Symposium, November 1995.

4. Lyons, J., et al., "Leveling the Playing Field for Hybrid Electric Vehicles: Proposed Modifications to California Air Resources Board's LEV Regulations," Sierra Research, Inc., June 9, 1993.
5. Duoba, M., et al., "Response to California Air Resources Board LEV Program Amendments Concerning Hybrid Electric Vehicles," memo for CARB, November, 1995.

6. Duoba, M. et al., "Testing Hybrid Electric Vehicle Emission and Fuel Economy at the 1994 DOE/SAE Hybrid Electric Vehicle Challenge," SAE Paper 950177, February, 1995.

7. Anderson, C., et al., "The Effects of APU Characteristics on the Design of Hybrid Control Strategies for Hybrid Electric Vehicles," SAE Paper 950493, February, 1995.

\section{ACKNOWLEDGMENT}

The work described in this paper was supported by the U.S. Department of Energy, Assistant Secretary for Energy Efficiency and Renewable Energy, under contract W-31-109-ENG-380.

\section{APPENDIX}

Table 3: Data for Various Hybrid Vehicles

\begin{tabular}{|c|c|c|c|c|c|c|c|}
\hline \begin{tabular}{c}
$\vdots$ \\
School \\
$\because \cdots$ \\
\hdashline
\end{tabular} & $\begin{array}{l}S \\
\text { or } \\
\text { or } \\
\mathbf{p}^{2}\end{array}$ & $\begin{array}{l}\text { Electr } \\
\text { Motor } \\
\text { (kW) }\end{array}$ & $\begin{array}{c}\text { Batt } \\
(\mathrm{kWh})\end{array}$ & $\begin{array}{l}\text { Engine } \\
(\mathrm{kWw})\end{array}$ & $\begin{array}{l}\text { Fuel } \\
\text { Econ } \\
(\text { knoth })\end{array}$ & $\begin{array}{l}1 / 8 \mathrm{mi} \\
\text { accel } \\
\text { (sec) }\end{array}$ & $\begin{array}{l}\text { Added } \\
\text { wit to veh } \\
(\mathrm{kg})\end{array}$ \\
\hline Neons & \multicolumn{3}{|c|}{1995 stock data: } & 100 & 12.3 & unavail & $0^{e}$ \\
\hline Tx Tech & $P$ & 15 & 3.2 & 104 & 10.2 & 11.1 & 365 \\
\hline Florida & $S$ & 32 & 8.1 & 15 & - & 15.8 & 469 \\
\hline UIC & $\mathbf{P}$ & 110 & 6.6 & 26 & - & 14.2 & 418 \\
\hline Tenn & $\mathbf{P}$ & 32 & 4.2 & 37 & 9.8 & 14.0 & 286 \\
\hline VI Tech & $\mathbf{S}$ & 77 & 3.7 & 41 & - & 13.0 & 391 \\
\hline W. Wash & $\mathbf{P}$ & 32 & 5.5 & 90 & 9.4 & 11.2 & 366 \\
\hline Saturns & \multicolumn{3}{|c|}{1995 stock data: } & $63,92^{f}$ & 12,11 & unavail & $0^{e}$ \\
\hline Chico & $S$ & 150 & 30.8 & 19 & 13.6 & 10.3 & 516 \\
\hline Fresno & $\mathbf{P}$ & 40 & 3.2 & $\cdot 75$ & 11.5 & 11.8 & 245 \\
\hline Cedarvil. & $S$ & 32 & 3.2 & 67 & - & - & 416 \\
\hline GMI & $S$ & 45 . & 3.6 & 13 & $17.9(94)$ & 15.6 & 378 \\
\hline IIT & $\mathbf{P}$ & 30 & 12.6 & 37 & 7.2 & 13.8 & 464 \\
\hline Maryl'nd & $\mathbf{P}$ & 19 & 3.3 & 45 & $17(94)$ & & 334 \\
\hline UT Aust. & $P$ & 47 & 5.4 & 56 & 11.1 & 17.4 & 211 \\
\hline W. Ont. & $\mathbf{P}$ & 22 & 3.0 & 45 & 4.7 & 25.8 & 308 \\
\hline Went'th & $\mathbf{P}$ & 42 & 6.7 & 73 & -- & 15.5 & 561 \\
\hline Fords & \multicolumn{3}{|c|}{1992 stock data: } & $71,95^{f}$ & 14,12 & unavail & $0^{e}$ \\
\hline Penn St. & $S$ & 68 & 13.6 & 16 & 2.6 & 14.6 & 459 \\
\hline Navy & $S$ & 56 & 15.4 & 16 & 8.9 & 14.0 & 395 \\
\hline Alberta & $P$ & 32 & 10.3 & 41 & $13.6(94)$ & 11.7 & 374 \\
\hline Wiscon. & $S$ & 75 & 8.0 & 16 & 9.4 & 14.2 & 469 \\
\hline W'yne St. & $\mathbf{P}$ & 36 & 5.8 & 67 & 11.5 & 11.4 & 557 \\
\hline W Vir. & $S$ & 44 & 11.0 & 16 & $20.4(24)$ & 15.6 & 432 \\
\hline \multicolumn{8}{|l|}{ Grd-ups } \\
\hline Cornell & $S$ & 56 & 19.32 & 41 & - & - & - \\
\hline LTU & $\mathbf{P}$ & 39 & 22.0 & 40 & - & - & - \\
\hline UC Davis & $\mathbf{P}$ & 44 & 15.7 & 13 & $14.9(94)$ & - & - \\
\hline Tulsa & $S$ & 41 & 12.6 & 9 & $11.1(94)$ & -- & - \\
\hline
\end{tabular}

All data from 1995 HEV Challenge, unless noted with by (94).

a $S=$ Series Contiguration. $P$ = Parallel Configuration

b Some vehicles used alternative fuels, their fucl economies are expressed in equivalent $\mathrm{km} / \mathrm{L}$

c Standing $1 / 8$ mi acceleration time from Accelerntion Event.

d The measured vehicle weight - stock vehicle curb weight.

c Stock vehicle weights: Neon 2332 lb., Saturn 2294 lb., Escort 2404 lb.

if Data for both engine options are given for power and fuel economy. 